\title{
BMJ Open Assessment of healthcare costs of amputation and prosthesis for upper and lower extremities in a Qatari healthcare institution: a retrospective cohort study
}

\author{
Hassan Al-Thani, ${ }^{1}$ Brijesh Sathian, ${ }^{2}$ Ayman El-Menyar ${ }^{2,3}$
}

To cite: Al-Thani H, Sathian B, El-Menyar A. Assessment of healthcare costs of amputation and prosthesis for upper and lower extremities in a Qatari healthcare institution: a retrospective cohort study. BMJ Open 2019;9:e024963. doi:10.1136/ bmjopen-2018-024963

- Prepublication history for this paper is available online. To view these files,please visit the journal online (http://dx.doi org/10.1136/bmjopen-2018024963).

Received 24 June 2018 Revised 14 November 2018 Accepted 15 November 2018

Check for updates

(c) Author(s) (or their employer(s)) 2019. Re-use permitted under CC BY-NC. No commercial re-use. See rights and permissions. Published by BMJ.

${ }^{1}$ Department of Surgery, Trauma and Vascular Surgery, Hamad General Hospital, Doha, Qatar ${ }^{2}$ Department of Surgery, Trauma and Vascular Surgery, Clinical Research, Hamad General Hospital, Doha, Qatar ${ }^{3}$ Clinical Medicine, Weill Cornell Medical School, Doha, Qatar

Correspondence to Professor Ayman El-Menyar; aymanc065@yahoo.com

\section{ABSTRACT}

Objectives To evaluate the healthcare cost of amputation and prosthesis for management of upper and lower extremities in a single institute.

Design Retrospective cohort study conducted between 2000 and 2014.

Participants All patients who underwent upper (UEA) and lower extremities amputation (LEA) were identified retrospectively from the operating theatre database. Collected data included patient demographics, comorbidities, interventions, costs of amputations including hospitalisation expenses, length of hospital stay and mortality.

Outcome measures Incidence, costs of amputation and hospitalisation according to the level of the amputation and cost per bed days, length of hospital stay and mortality.

Results A total of 871 patients underwent 1102 (major 357 and minor 745) UEA and LEA. The mean age of patients was $59.4 \pm 18.3$, and $77.2 \%$ were males. Amputations were most frequent among elderly (51.1\%). Two-third of patients $(75.86 \%, 95 \% \mathrm{Cl} 72.91 \%$ to $78.59 \%)$ had diabetes mellitus. Females, Qatari nationals and non-diabetics were more likely to have higher mean amputation and hospital stay cost. The estimated total cost for major and minor amputations were US\$3 797930 and US\$2 344439 , respectively. The cumulative direct healthcare cost comprised total cost of all amputations, bed days cost and prosthesis cost and was estimated to be US\$52 126496 and per patient direct healthcare procedure cost was found to be US\$59847. The total direct related therapeutic cost was estimated to be US\$26 096046 with per patient cost of US\$29961. Overall per patient cost for amputation was US\$89808.

Conclusions The economic burden associated with UEA and LEA-related hospitalisations is considerable. Diabetes mellitus, advanced age and sociodemographic factors influence the incidence of amputation and its associated healthcare cost. The findings will help to showcase the economic burden of amputation for better management strategies to reduce healthcare costs. Furthermore, larger prospective studies focused on cost-effectiveness of primary prevention strategies to minimise diabetic complication are warranted.
Strengths and limitations of this study

- Large sample of patients who underwent upper and lower extremities amputation.

- This study used microcosting and case-mix group methods for healthcare cost analysis.

- There is a lack of information about the cost of outpatient care and rehabilitation services.

- All amputations were performed in the only tertiary centre in Qatar (2000-2014)

- The study focused mainly on diagnostic and therapeutic costs but did not include indirect costs.

\section{INTRODUCTION}

Limb amputation remains a major problem worldwide in spite of the advancement in the diagnostic and therapeutic measures. In the USA, 1.6 million people were estimated to be living with limb loss in 2005, of them $65 \%$ had lower extremity amputation (LEA). ${ }^{1}$ However, upper extremity amputation (UEA) is relatively rare $(8 \%)$ and mostly related to traumatic injury $(68.6 \%){ }^{1}$

According to the recent WHO estimates, around 150 million individuals are affected by diabetes mellitus (DM) globally; and this figure is expected to be twofold by the year 2025. ${ }^{2}$ The risk of LEA is considerably higher (10-fold) in patients with DM as compared with non-diabetics. ${ }^{3}$ Nearly, $75 \%$ of the LEAs are performed in the patients with diabetic foot disease. ${ }^{45}$ Also, LEA is associated with higher risk of mortality, impaired quality of life and increased healthcare costs among diabetics. ${ }^{6}$ Early initiatives perused the goal to reduce the number of LEAs in patients with diabetes. ${ }^{7} 8$ However, epidemiological studies have shown marked variations in the incidence, relative risks and time trends and management of LEA in diabetic compared with non-diabetic population, 
owing to differences in study design and methodological approaches. ${ }^{59}$

Furthermore, the treatment strategies of LEA should carefully account for the associated complications, quality of life and healthcare cost. Lower Extremity Assessment Project study revealed similar functional outcomes in patients underwent amputation or reconstruction of the limb-threatening lower extremity injury. ${ }^{10}$ An earlier meta-analysis, based on nine observational studies also found no significant difference in terms of functional outcome of patients with leg-threatening injuries treated either with limb salvage or primary amputation on follow-up. ${ }^{11}$ It has been suggested that the functional outcomes are often improved after successful limb reconstruction in comparison to early amputation and appropriate prosthesis. ${ }^{12} 13$ Also, some studies concluded that the cost of amputation is less as compared with limb salvage and early amputation is a reasonable cost-effective strategy. ${ }^{1114}$ Although, reconstructive limb salvage is technically challenging and time-consuming, some investigators suggested that it is associated with improved quality of life and lesser costs of treatment as compared with amputation. ${ }^{1516}$ Notably, in Qatar the prevalence of diabetes is rapidly increasing with an escalating problem of diabetic foot disorder that necessitates amputation. ${ }^{17}$ Currently, there is a lack of integrated facility to treat diabetic foot ulceration which may compromise the quality of life, with lower productivity, higher medical cost and unnecessary amputations. Therefore, cost of illness (COI) analysis for diabetics and non-diabetics is imperative to provide the scientific evidence for making appropriate clinical decisions, cost-saving and resource allocation. In addition, it could be beneficial for improvement in preventative diabetic foot care, avoidance of unfavourable outcomes and will be a basis for formulation of health policies and fiscally sound decisions to improve healthcare facilities. Considering the expanding need and limitation of healthcare resource, this study presents the healthcare costs of amputation and prosthesis for management of upper and lower extremities in a tertiary healthcare institution of Qatar.

\section{METHODS}

\section{Study population and settings}

It was a retrospective cohort study based on data obtained from the operating theatre database and medical records at Hamad General Hospital (HGH) for all patients who underwent UEA and LEA between 2000 and 2014. Median follow-up time was 19 with an IQR of 3-53 months. All patients with major and minor amputation were included in the study. Primary healthcare and tertiary referral care centres comprised the healthcare system in Qatar. HGH is the referral hospital that provides basic healthcare facilities to manage high-risk patients for amputation who require elective and emergency surgery including trauma and vascular management. During the study period, there was no provision of health insurance scheme and all emergency services were provided free of cost to patients. Both nationals and expatriates with valid resident permit used to have equal access to health facilities. All in-hospital diagnostic and therapeutic services are available free of charge at $\mathrm{HGH}$ for all nationals and residents in Qatar, whereas costs of prosthesis are covered by private or charity agencies for residents. HGH is the only tertiary hospital in Qatar performing amputations during the study period.

\section{Data collection}

Data were collected on patient demographic characteristics (age, gender and nationality), DM status, intervention details (indications, level of amputation, major and minor amputation) and part (limb or digit) amputated, length of hospital stay and early mortality. We obtained data for the cost of amputation and hospitalisation according to the level of the amputation (toe, finger, forefoot/hind foot, above/below knee, wrist level, above/below elbow) and cost per bed days. The procedure and material cost was included in the level of amputation cost.

The sessions were categorised as major amputations, which involved below-knee and above-knee amputation, whereas minor amputations referred to the sessions involving digit (toe or finger) and transmetatarsal amputations. Amputations were further classified based on involvement of single or multiple extremities. The major indication for amputation was diabetic foot ulcer with or without ischaemia followed by traumatic injury and tumour. The diagnosis of DM was considered based on patient's history of diabetes and/or current antidiabetic management such as insulin therapy and oral hypoglycaemic agent.

\section{Patient and public involvement}

Patients and public were not involved in this study, because it is a retrospective cohort study and data were collected anonymously.

\section{Cost analysis}

COI studies are needed for justification of budget, establishment of preventive and interventional programmes and setting up priorities for research funding by healthcare policy makers. ${ }^{45}$ Depending on the objective of cost analysis, it can be either based on prevalence or incidence of the disease. Prevalence is more commonly considered for budget planning and decision making by health policy makers. ${ }^{18}$ This includes calculation of total costs for a study population over particular period of time in a specified area. ${ }^{18} 19$ For health economics research, medical costs and disease-associated costs are the two main criteria considered for cost evaluation. ${ }^{19} 20$ These medical costs are further subclassified as direct (types of payments and expenses) and indirect (resource utilisation). ${ }^{19} 20$ The direct cost involves costs incurred for in-hospital and outpatient services, medical supplies, laboratory investigations, medication, rehabilitation services at care centres, home and caregiver costs. Costs 


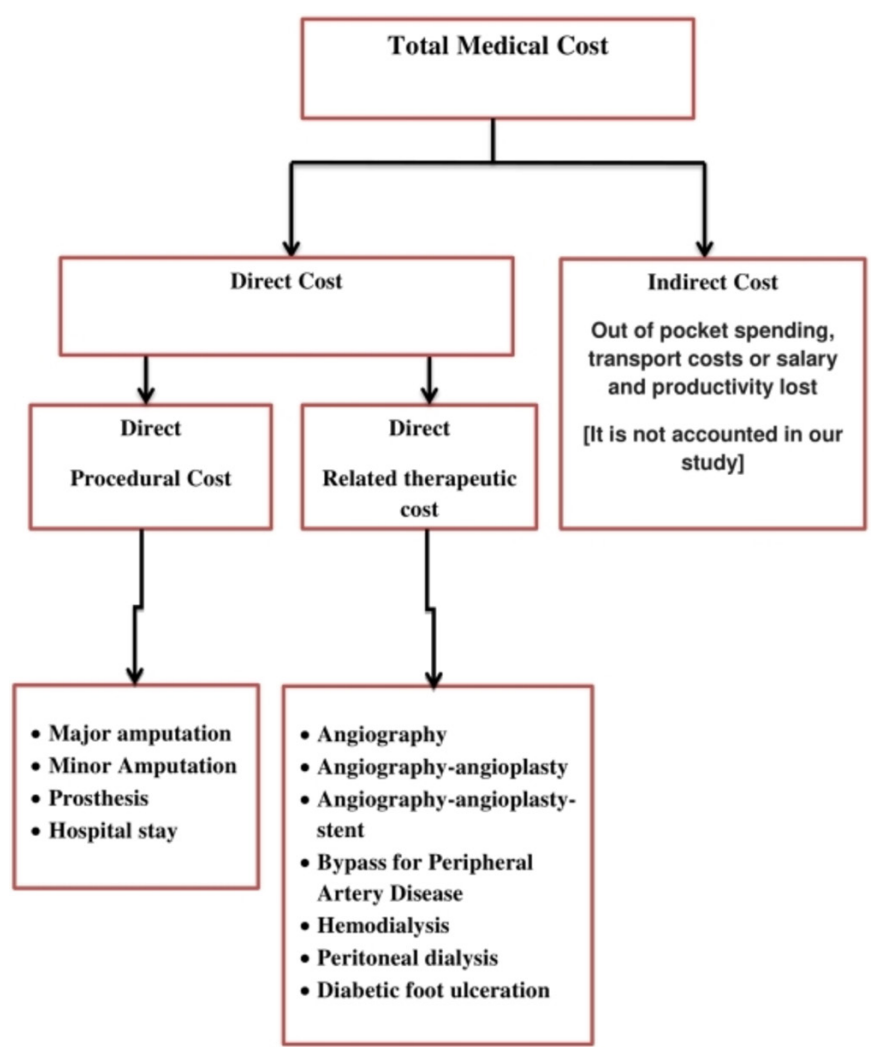

Figure 1 Overview of total medical cost analysis flow diagram.

of resources that are lost due to morbidity and mortality referred as indirect costs. ${ }^{19}$

Overall cost=amputation cost + hospital stay cost + prosthesis cost+angiographyalone cost+angiography/angioplasty cost+angiography/angioplasty/stent cost+bypass for peripheral artery disease cost+diabetic foot ulceration cost + haemodialysis cost+peritoneal dialysis cost.

The cost of amputation and hospitalisation were calculated using a microcosting methodology, whereas the prosthesis and therapeutic cost were calculated using case-mix group method. This study includes all amputation cases data from a national tertiary centre for a period of 14 years. It also addresses an overview of the clinical progress of a 14-year amputee population. By following this cohort from their initial procedure until rehabilitation, leaving the country or mortality, it provides the reader with valuable insights into the demographic pattern, risk factors, clinical presentation, economic burden, management and outcomes.

\section{Evaluation of amputation costs}

The total medical cost of upper and lower limb amputation was calculated by multiplying the number of amputations, hospital stays, prosthesis and therapeutic interventions with the respective unit costs. Figure 1 shows the overview of total medical cost analysis. The direct medical costs were also computed for amputations, hospital stays and prosthesis. The direct related (therapeutic) medical cost evaluation in this study mainly comprised procedural cost involving angiography, angiography/angioplasty,
Table 1 Estimated cost of service-summary

\begin{tabular}{lc}
\hline Procedure & Cost (in US\$) \\
\hline Level of amputation & \\
\hline Toe & 2068 \\
Finger & 2169 \\
\hline Forefoot/hind foot & 10639 \\
Above/below knee & 10639 \\
Wrist level & 10639 \\
Above/below elbow & 10639 \\
Per bed days & 1236 \\
Prosthesis & \\
\hline Prosthesis fabrication & 6415 \\
Fitting of prosthesis and training & 736.3 \\
\hline Total cost for prosthesis & 7151 \\
\hline Therapeutic & 684 \\
\hline Angiography & 1033 \\
Angiography-angioplasty & 2398 \\
Angiography-angioplasty-stent & 3115 \\
Bypass for peripheral artery disease & 653845 \\
Diabetic foot ulceration & 341 \\
\hline Haemodialysis & 640 \\
\hline Peritoneal dialysis & \\
\hline
\end{tabular}

angiography/angioplasty/stent, bypass for peripheral artery disease, management cost of diabetic foot ulceration, haemodialysis and peritoneal dialysis. All costs are represented in US dollars.

The institutional medical cost was obtained from the 'Estimated Cost of Service-Summary', cost accounting section, finance department, Hamad Medical Corporation, Doha, Qatar (table 1).

\section{Data management and statistical analysis}

Descriptive and inferential statistics were applied for data analysis. Cost estimates are presented as point estimates with $95 \%$ CIs, which were used to generalise the percentages. Linear regression analysis and scatter plot were used to find out the correlation between variables. Data were analysed using R V.3.5.1 and Statistical Package for the Social Sciences (SPSS) for Windows V.21.0 (SPSS, Chicago, Illinois, USA).

\section{RESULT}

\section{Sociodemographic characteristics}

A total of 871 patients underwent 1102 (major 357 and minor 745) upper and lower extremities amputation over the 14-year study duration. The mean age of patients was $59.4 \pm 18.3,77.2 \%$ (95\% CI 74.25 to 79.82 ) were males and $37.4 \%$ were citizens (table 2). Amputations were most frequent in the age group $>60$ years $(51.1 \%)$ followed by $41-60$ years $(33.2 \%)$ and $\leq 40$ years $(15.7 \%)$. The majority of patients $(75.9 \%, 95 \%$ CI $72.91 \%$ to $78.59 \%)$ were 
Table 2 Comparison of amputation and hospital stay cost stratified by demographics, aetiology and early mortality $(n=871)$ in US\$

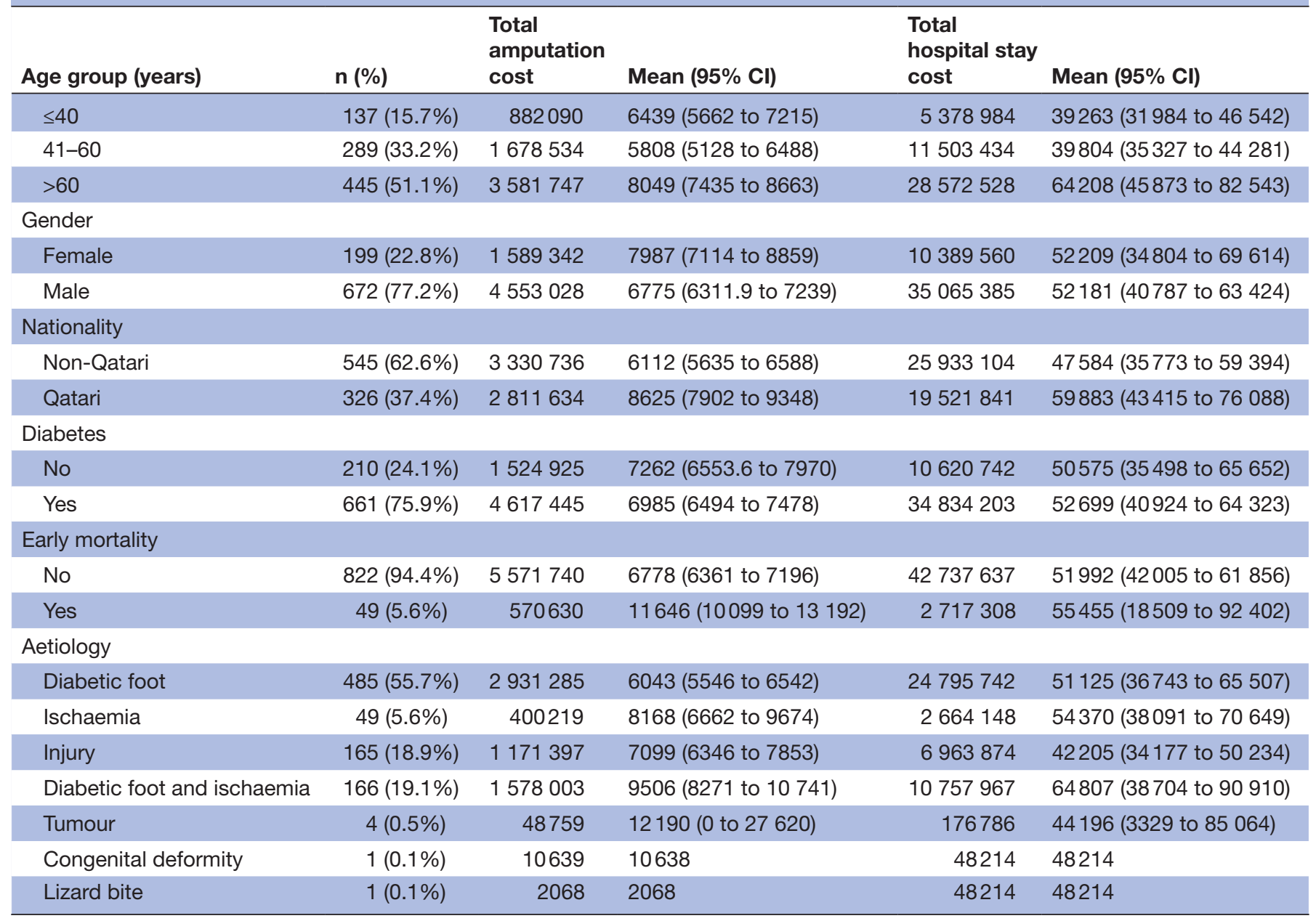

diabetics. The most common indication for amputation was diabetic foot complications $(74.8 \%)$, followed by trauma $(18.9 \%)$ and ischaemia $(5.6 \%)$.

\section{Cost analysis}

Analysis of the cost of amputation and hospital stay stratified by sociodemographic factors, aetiology and early mortality are shown in table 2 . The total and mean amputation and hospital stay cost were highest for elderly patients ( $>60$ years) as compared with other age groups. However, females, Qatari nationals and patients with no diabetes were more likely to have higher mean amputation and hospital stay cost even though the total cost was more in their counterparts. Also, early mortality accounted for higher mean cost of amputation and hospital stay but the total cost for both was relatively lower as compared with those who survived.

Table 3 shows analysis of the cost of amputation according to level of amputation. A total of 357 patients underwent major amputations in the index admission and on follow-up with an estimated total cost of US\$3 797931 and 745 patients required minor amputations which were estimated to cost US\$2 344439. As per the level of amputation, below-knee $(n=172)$ and above-knee ( $\mathrm{n}=164)$ amputations involved in maximum cost with a total estimate of US\$1 829815 and US\$1 744708 , respectively.

Table 4 represents the estimated cost of hospital stay according to the level of amputation. For major and minor amputations, the hospital cost was estimated to be US\$21 351511 and US\$24 103 434, respectively. Toe amputations incurred maximum total cost (US\$21 454 121) followed by above-knee (US\$13 778 159) and below-knee (US\$6 815 522) amputations.

The cumulative direct healthcare cost comprised the total cost of all amputations US\$6 142370 (mean: 7052; $95 \%$ CI 6642 to 7462 ), total bed days cost US\$45 454945 (mean: 52 187; 95\% CI 42618 to 61756 ) and total prosthesis cost $(n=74)$ US $\$ 529181$. Therefore, the total direct healthcare cost was estimated to be US\$52 126496 , and per patient direct healthcare cost was found to be US\$59 846.

Table 5 represents the estimated total cost (amputation cost+hospital stay cost) according to the level of amputation. For major and minor amputations, the hospital cost was estimated to be US\$25 149442 and US\$26 447873 , respectively. 


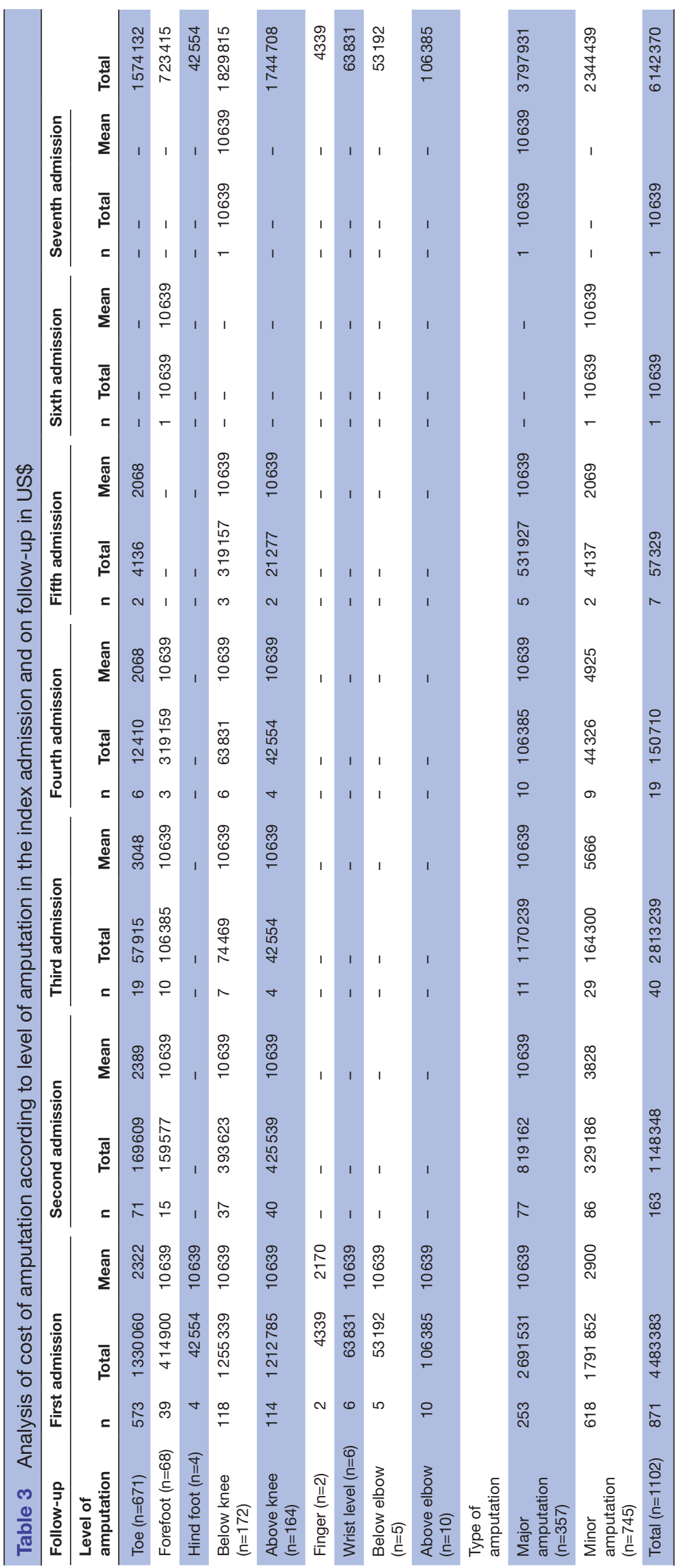




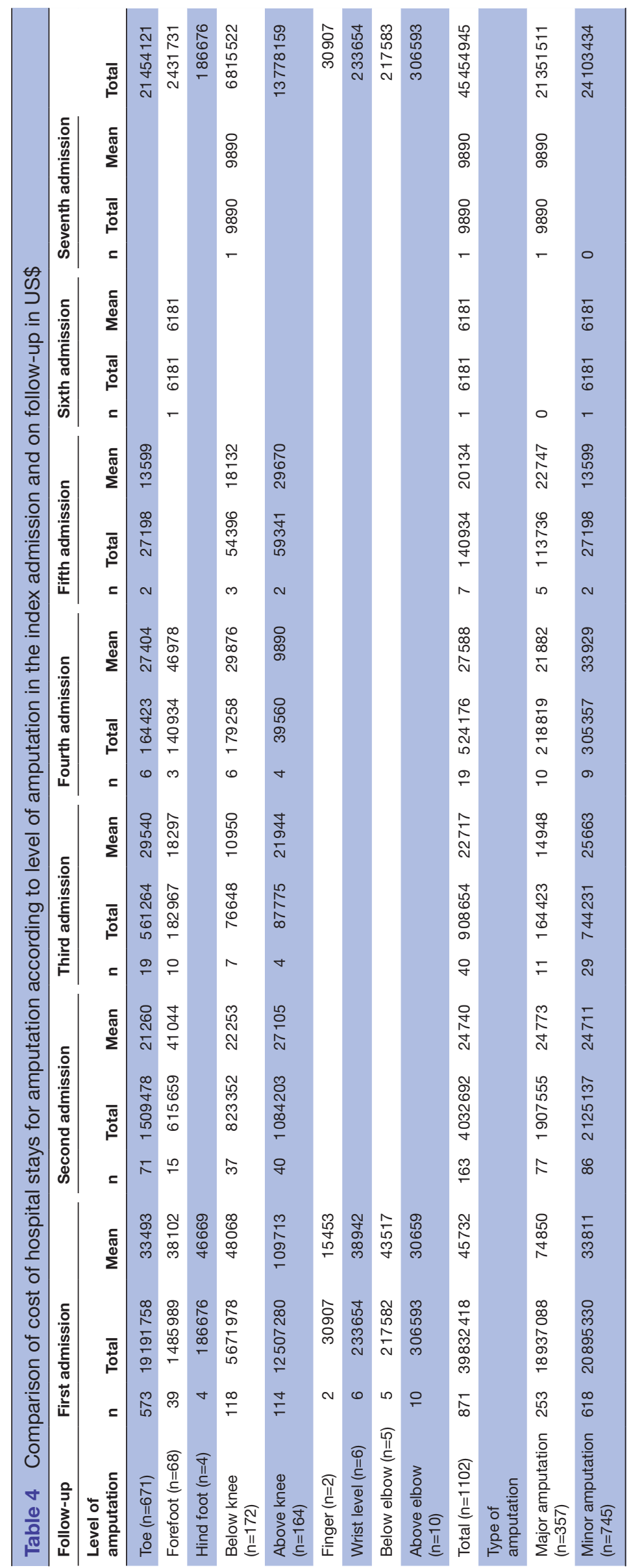

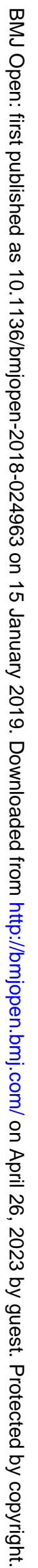




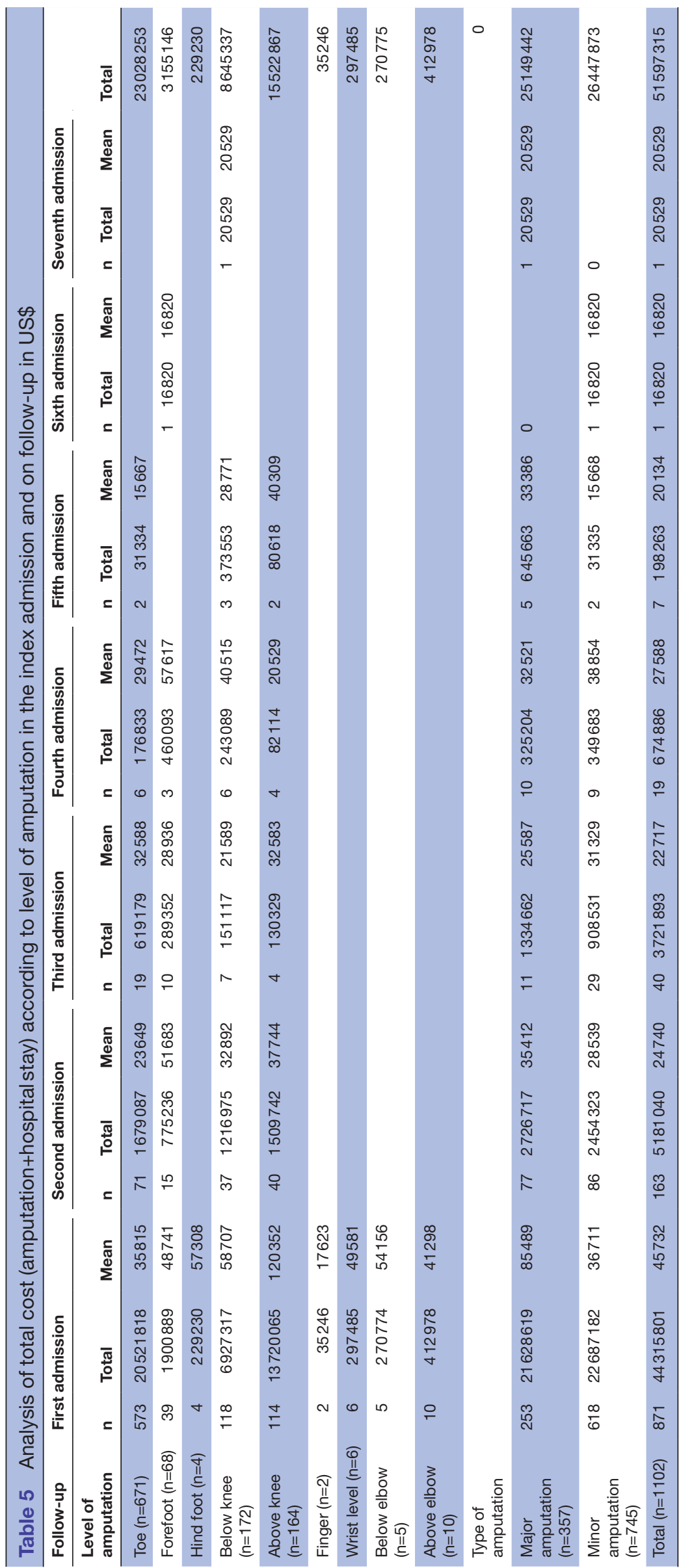

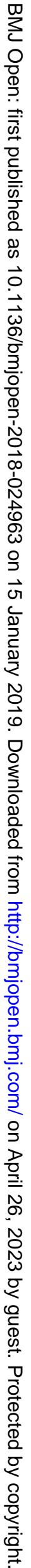


Table 6 Direct related therapeutic interventions cost of amputation in US\$

\begin{tabular}{llllr}
\hline & & & \multicolumn{2}{c}{ Total length of hospital } \\
stay (days) & Total cost \\
\hline Therapeutic interventions & & Frequency (n) & & 58824 \\
Angiography alone & 684 & 86 & - & 60760 \\
Angiography-angioplasty & 868 & 70 & - & 21582 \\
\hline Angiography-angioplasty-stent & 2398 & 9 & - & 171325 \\
Bypass for peripheral artery disease & 3115 & 55 & - & 24590940 \\
\hline Diabetic foot ulceration & 55385 & 444 & - & 515495 \\
\hline Haemodialysis & 341 & 132 & 5291 & 677120 \\
\hline Peritoneal dialysis & 640 & 25 & 1058 & 26096046 \\
\hline Total & - & - & - & \\
\hline
\end{tabular}

Table 6 demonstrated the estimation of direct related therapeutic interventions cost of amputation. The total direct related therapeutic interventions cost was estimated to be US $\$ 26096046$. Haemodialysis (US\$515 495), management of diabetic foot ulceration (US\$24 590 940) and peritoneal dialysis (US\$677 120) accounted for the major direct therapeutic cost.

\section{Regression analysis}

Overall cost $=36458.27+1.02$ hospital stay cost

There was a positive strong correlation between overall cost and hospital stay cost $\left(\mathrm{r}^{2}=0.96, \mathrm{p}=0.00001\right)$. Other variables showed a weak correlation $\left(\mathrm{r}^{2}<0.30\right)$. Hospital stay cost was an independent predictor of overall cost. Figure 2 depicts the correlation between overall cost and the regression adjusted predicted value.

\section{DISCUSSION}

To the best of our knowledge, this is the first study on healthcare cost associated with amputation and prosthesis in the Arab Middle East region. We estimated the association between patient demographics, characteristics, DM, mortality and direct medical costs of upper and lower extremities amputation managed at a tertiary care institution over 14 years. Despite some limitations, the present study attempts to estimate the economic burden of extremity amputation on the healthcare system. The study revealed that the total direct healthcare cost of amputation per patient in Qatar was US $\$ 89808$. The expected management cost is considerable and varies according to patients characteristics.

In the present study, the mean age of patients was 59 years and amputations were performed mostly among the elderly group. Prior population-based studies reported a mean age of 65 years in patients with LEA. ${ }^{21} 22$ Moreover, females, Qatari nationals and patients with no diabetes were more likely to have higher mean amputation and hospital stay cost in our study cohort; however, the total cost of amputation and hospital stay remains higher among males, non-Qataris and diabetics. Lefebvre and Chevan $^{23}$ suggested that females were more likely to undergo major amputation than males which could be attributed to delayed presentation of women with vascular disease. Furthermore, female usually have a longer time for the diagnosis of DM, and its associated complications which might result in higher costs. ${ }^{24}$

The current analysis extends the previous results to demonstrate that the total costs are higher in patients with DM than patients with no diabetes. ${ }^{25}$

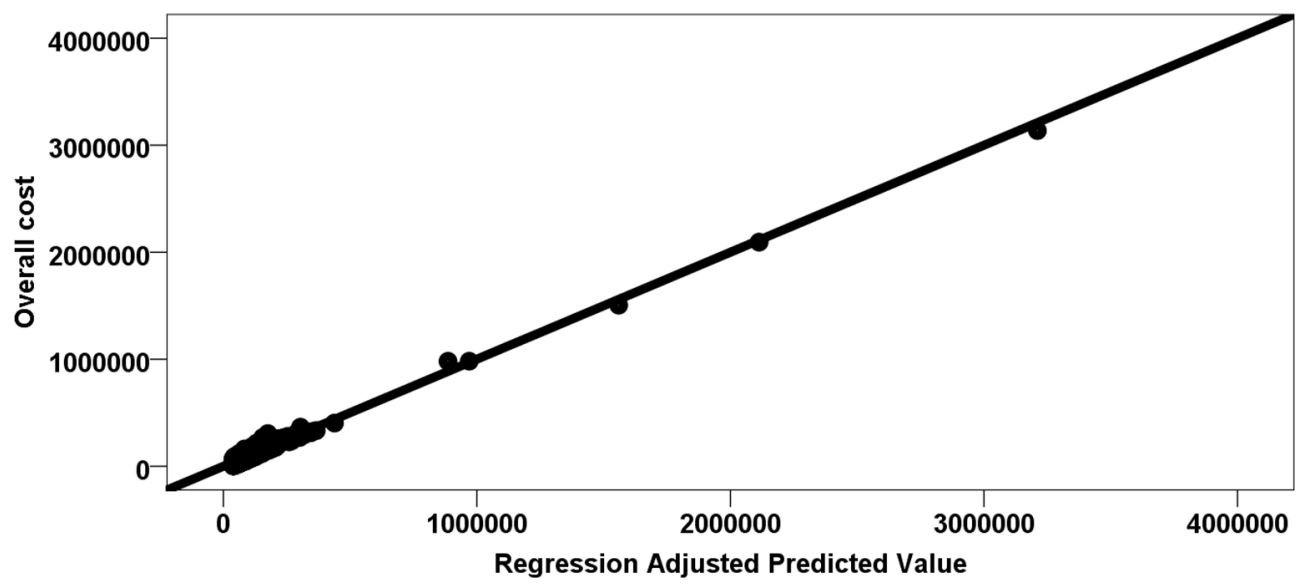

Figure 2 Scatter plot of the overall cost and regression adjusted predicted value. 
The global incidence of LEA has dispersion because of population heterogeneity. Even though there is a declining trend over time but the incidence rate of LEA remains high. In our study, $67 \%$ of amputations were minor in nature. Globally, there exists a higher incidence of LEA among diabetics which ranges from 46.1 to 9600 per 100000 population than those without DM (5.8-31 per 100000 population). ${ }^{26}$ Similarly, our study showed that the majority of amputations were done in patients with diabetes $(75.86 \%, 95 \%$ CI $72.91 \%$ to $78.59 \%)$. An earlier study reported a high prevalence of DM (16.7\%) in adult Qatari population. ${ }^{27}$ In our study, the mean amputation cost was US\$6985 and mean hospital stay cost was US\$52699 among diabetics. Brandle et $a l^{28}$ found the median cost of an amputation as US\$37600 (US\$23 300-US\$62 200) in 2003. The present study reported a higher overall total direct healthcare cost of amputation per patient which was found to be US $\$ 59846$. Similar to our estimates, Margolis $e t a l^{29}$ reported that the mean total annual Medicare payments for any beneficiary with diabetes-related LEA were roughly US $\$ 52000$ in 2008. Rinkel $e t a l^{30}$ study on patients with diabetic foot disease, revealed an average in-hospital costs to be US $\$ 10827$ (range: 702-82 880) per episode. The average cost of single minor amputation, multiple minor amputations and major amputations were US $\$ 13580$, US $\$ 31835$ and US $\$ 73813$ per episode, respectively. Mundell $e t a l^{31}$ identified the mean medical costs for transfemoral amputations of hospitalised patients as US\$25652 (95\% CI US $\$ 10468$ to US\$38 872) and emergency department as US $\$ 18091$ (95\% CI US $\$ 7820$ to US $\$ 57$ 368). Franklin $e t$ $a l^{32}$ reported in a study that mean cost of care for patients with diabetes in US veterans with lower limb amputation for all amputation level was US\$60647 (95\% CI US\$59 143 to US\$62 188), for toe was US $\$ 41484(95 \%$ CI US $\$ 40075$ to US $\$ 42943$ ), below knee was US $\$ 71067$ (95\% CI US\$68 449 to US\$73 785) and above knee was US\$82758 (US\$78 063 to US\$87 736).

Table 7 shows the prevalence of DM in the Arab Middle Eastern region ranges from $1.88 \%$ to $25.5 \% .{ }^{2733-65}$ Diabetes-related complications could be serious and necessitate prolonged hospitalisation, and in some cases, it might need major surgical intervention. Hospital cost remains the highest cost component for the management of diabetic foot ulceration (DFU). Improvement of the preventive measures and patient management will result in a reduction of total healthcare costs of the related disease. The second leading component of cost is the pharmacy cost. Among these costs, antithrombotic drugs have the largest share. Increased use of generic antithrombotic drugs may be a powerful factor for reducing this cost.

Harrington et $a b^{65}$ reported the average ulcer-related cost per year to be US\$3609. Our study had 444 patients with DFU, which contributed the average ulcer-related cost per year to be US\$3956. Stockl et at $t^{66}$ found the average ulcer episode cost as US\$13179. In our study, the total ulcer episode cost for Qatar was US\$5 851476.
Barceló $e t a l^{67}$ estimated the cost of permanent disability caused by DM. Similarly, we have attempted to assess the cost of disability using the formulae, 'The estimated cost of permanent disability=number of productive years lost to disability $\times$ the per capita gross domestic product (GDP)'. According to the GDP, Qatar comes under the high-income group with a per capita indirect cost of US $\$ 7959$ for DM. Based on this, total per capita indirect cost of DM was US\$44 196327 between the year 2000 and 2014 in our study.

An earlier study from the United Arab Emirates ${ }^{25}$ reported the annual mean treatment cost to be US $\$ 5645$, which is comparatively higher than the estimated cost per patient per year US\$3990 in the present study.

According to the WHO Qatar report 2016, around 38000 individuals are diagnosed with DM, which is predicted to increase to 88000 by $2030 .{ }^{33}$

Appropriate and efficient treatment of DM could significantly prevent or reduce vascular complications. Therefore, prevention of complication related to DFU is considered as the most effective means of healthcare cost reduction.

Another alternative to minimise the cost is delaying the complication as long as possible. For prevention of DFU, it is useful to train the high-risk patients and to spread awareness among patients with diabetes which have implications for cost savings. ${ }^{68}$ The present study revealed a high cost of amputation and prosthesis. Findings of our analysis have implications to inform healthcare policy makers about the financial burden of amputations and urge the need for effective planning to improve outcomes of DM in Qatar.

A major limiting factor of the present study is the retrospective nature; therefore, the collected data might have missing information about the exact duration of diabetes. We might have underestimated the total costs as we mainly focused on the direct medical costs and cost of therapeutic interventions but did not include, payments incurred by patient, out-of-pocket costs, direct non-medical costs or other indirect costs.

We could not account pharmacy-related costs separately. The laboratory and radiological investigations, medical supplies and medications that were directly used during the course of treatment, and non-medical direct expenses were not considered in cost evaluation due to lack of sufficient data. In addition, it is imperative to know the indirect costs associated with work loss hours and residual disability. This study did not account for the indefinite costs involving pain, distress, depression, suffering and stress caused by amputation. Also the indirect costs of amputation from the societal perspective resulted in disabilities, lost productivity on the part of the patient, or premature mortality were not taken into consideration. This cost analysis study has other limitations such as lack of information about the cost of outpatient care and use of resource for chronic diseases, like hospital or home-based rehabilitation after amputation or other diabetic complications. We attempted to remove 
Table 7 Prevalence of diabetes and diabetic foot complications in the Arab population

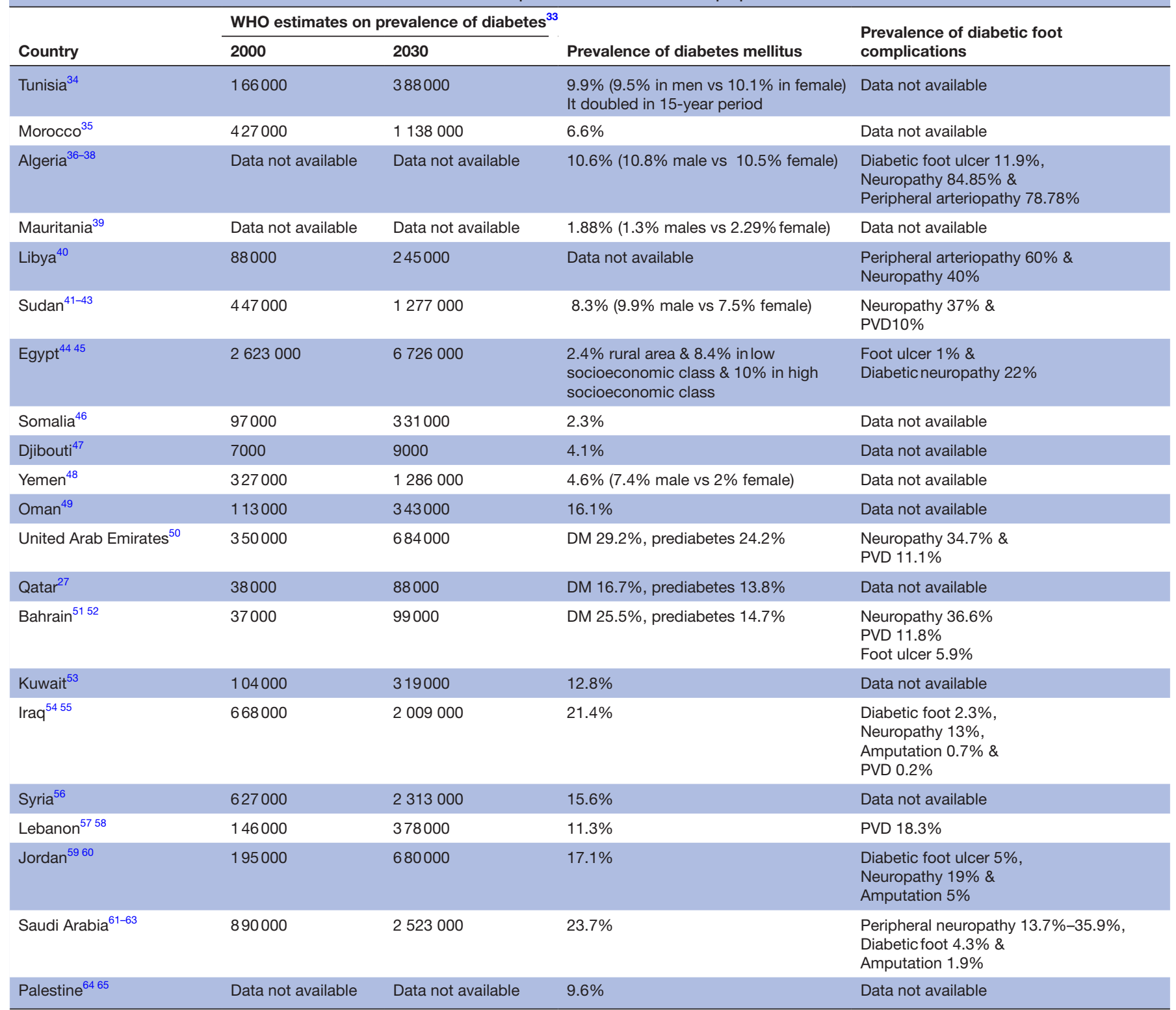

PVD, peripheral vascular disease.

uncertainty as much as possible by getting good quality data, to obtain a more accurate and standardised cost estimates from the hospital finance accounting. This study has a good external validly of results because all the amputation cases were managed in our national centre.

\section{CONCLUSIONS}

The economic burden associated with upper and lower extremity amputation-related hospitalisations is considerable. DM, advanced age and sociodemographic factors influence the incidence of amputation and its associated healthcare cost in Qatar.

The findings of this study will help to showcase the economic burden of amputation, which will be the basis for better management to reduce healthcare costs. There is an urgent need for effective standardised institutional screening protocol for minor and major extremity amputations among high-risk populations. Particularly, the effective approach to manage high-risk patients with diabetes includes an extensive patient education, early assessment and aggressive treatment by a multidisciplinary team. Furthermore, effective interventions may curb the otherwise impending clinical and economic burden of amputation in population with high prevalence of risk factors.

Acknowledgements The authors would like to thank the staff of Surgery Department of Hamad General Hospital in Doha, Qatar for their kind cooperation.

Contributors All authors were involved in study design, data acquisition, analysis, interpretation and writing manuscript.

Funding The authors have not declared a specific grant for this research from any funding agency in the public, commercial or not-for-profit sectors.

Competing interests None declared. 
Patient consent for publication Not required.

Ethics approval This study has been performed in accordance with the ethical standards laid down in the 1964 Declaration of Helsinki and its later amendment. This study obtained ethical approval from Research Ethics Committee, at Medical Research Center, Hamad Medical Corporation (HMC), Doha, Qatar (IRB\#14198/14).

Provenance and peer review Not commissioned; externally peer reviewed.

Data sharing statement № additional data are available to share.

Open access This is an open access article distributed in accordance with the Creative Commons Attribution Non Commercial (CC BY-NC 4.0) license, which permits others to distribute, remix, adapt, build upon this work non-commercially, and license their derivative works on different terms, provided the original work is properly cited, appropriate credit is given, any changes made indicated, and the use is non-commercial. See: http://creativecommons.org/licenses/by-nc/4.0/.

\section{REFERENCES}

1. Ziegler-Graham K, MacKenzie EJ, Ephraim PL, et al. Estimating the prevalence of limb loss in the United States: 2005 to 2050. Arch Phys Med Rehabil 2008;89:422-9.

2. World Health Organization (WHO). Diabetes mellitus. 2017. http:// www.who.int/mediacentre/factsheets/fs138/en/ (Accessed 15 Aug 2017).

3. Hoffstad O, Mitra N, Walsh J, et al. Diabetes, lower-extremity amputation, and death. Diabetes Care 2015;38:1852-7.

4. Trautner C, Haastert B, Spraul M, et al. Unchanged incidence of lower-limb amputations in a German City, 1990-1998. Diabetes Care 2001;24:855-9.

5. Almaraz MC, González-Romero S, Bravo M, et al. Incidence of lower limb amputations in individuals with and without diabetes mellitus in Andalusia (Spain) from 1998 to 2006. Diabetes Res Clin Pract 2012;95:399-405.

6. Narres M, Kvitkina T, Claessen $\mathrm{H}$, et al. Incidence of lower extremity amputations in the diabetic compared with the non-diabetic population: A systematic review. PLoS One 2017;12:e0182081.

7. Larsson J, Apelqvist J, Agardh CD, et al. Decreasing incidence of major amputation in diabetic patients: a consequence of a multidisciplinary foot care team approach? Diabet Med 1995;12:770-6.

8. Lavery LA, Ashry HR, van Houtum W, et al. Variation in the incidence and proportion of diabetes-related amputations in minorities. Diabetes Care 1996;19:48-52.

9. Icks A, Haastert B, Trautner C, et al. Incidence of lower-limb amputations in the diabetic compared to the non-diabetic population. findings from nationwide insurance data, Germany, 20052007. Exp Clin Endocrinol Diabetes 2009;117:500-4.

10. MacKenzie EJ, Bosse MJ, Kellam JF, et al. Early predictors of long-term work disability after major limb trauma. J Trauma 2006;61:688-94.

11. Busse JW, Jacobs CL, Swiontkowski MF, et al. Complex limb salvage or early amputation for severe lower-limb injury: a meta-analysis of observational studies. J Orthop Trauma 2007;21:70-6.

12. Langer V. Management of major limb injuries. ScientificWorldJournal 2014;2014:1-13.

13. Hertel R, Strebel N, Ganz R. Amputation versus reconstruction in traumatic defects of the leg: outcome and costs. J Orthop Trauma 1996;10:223-9.

14. Gil J, Schiff AP, Pinzur MS. Cost comparison: limb salvage versus amputation in diabetic patients with charcot foot. Foot Ankle Int 2013;34:1097-9.

15. Chung KC, Saddawi-Konefka D, Haase SC, et al. A cost-utility analysis of amputation versus salvage for Gustilo type IIIB and IIIC open tibial fractures. Plast Reconstr Surg 2009;124:1965-73.

16. MacKenzie EJ, Jones AS, Bosse MJ, et al. Health-care costs associated with amputation or reconstruction of a limb-threatening injury. J Bone Joint Surg Am 2007;89:1685-92.

17. Mohamed H. Diabetic foot in Qatar: A Primary Care Perspective. Qatar Foundation Annual Research Conference Proceedings:HBPP1084. 2016. http://www.qscience.com/doi/pdf/ (Accessed 15 Aug 2017).

18. Kobelt G. Kobelt G, ed. Forms of Health Economic Evaluation. Health economics: an introduction to economic evaluation. 3rd edn. London: Office of Health Economics, 2013:12-31.

19. Rice DP. Cost-of-illness studies: fact or fiction? Lancet 1994;344:1519-20.

20. Rice DP. Cost of illness studies: what is good about them? Inj Prev 2000;6:177-9.
21. Hussain MA, Al-Omran M, Mamdani M, et al. Efficacy of a GuidelineRecommended Risk-Reduction Program to Improve Cardiovascular and Limb Outcomes in Patients With Peripheral Arterial Disease. JAMA Surg 2016;151:742-50.

22. Costa RHR, Cardoso NA, Procópio RJ, et al. Diabetic foot ulcer carries high amputation and mortality rates, particularly in the presence of advanced age, peripheral artery disease and anemia. Diabetes Metab Syndr 2017;11(Suppl 2):S583-7.

23. Lefebvre KM, Chevan J. Sex disparities in level of amputation. Arch Phys Med Rehabil 2011;92:118-24.

24. Li R, Bilik D, Brown MB, et al. Medical costs associated with type 2 diabetes complications and comorbidities. Am J Manag Care 2013;19:421-30.

25. Al-Maskari F, El-Sadig M, Nagelkerke N. Assessment of the direct medical costs of diabetes mellitus and its complications in the United Arab Emirates. BMC Public Health 2010;10:679.

26. Moxey PW, Gogalniceanu P, Hinchliffe RJ, et al. Lower extremity amputations--a review of global variability in incidence. Diabet Med 2011;28:1144-53.

27. Bener A, Zirie M, Janahi IM, et al. Prevalence of diagnosed and undiagnosed diabetes mellitus and its risk factors in a populationbased study of Qatar. Diabetes Res Clin Pract 2009;84:99-106.

28. Brandle M, Zhou H, Smith BR, et al. The direct medical cost of type 2 diabetes. Diabetes Care 2003;26:2300-4.

29. Margolis DJ, Malay DS, Hoffstad OJ, et al. Economic burden of diabetic foot ulcers and amputations. Washington (DC): Agency for Healthcare Research and Quality, 2011.

30. Rinkel WD, Luiten J, van Dongen J, et al. In-hospital costs of diabetic foot disease treated by a multidisciplinary foot team. Diabetes Res Clin Pract 2017;132:68-78.

31. Mundell B, Maradit Kremers H, Visscher S, et al. Direct medical costs of accidental falls for adults with transfemoral amputations. Prosthet Orthot Int 2017;41:564-70.

32. Franklin $\mathrm{H}$, Rajan $\mathrm{M}$, Tseng $\mathrm{CL}$, et al. Cost of lower-limb amputation in U.S. veterans with diabetes using health services data in fiscal years 2004 and 2010. J Rehabil Res Dev 2014;51:1325-30.

33. WHO. Country and regional data on diabetes. 2017. http://www.who. int/diabetes/facts/world_figures/en/index2.html (Accessed 15 Aug 2017).

34. Bouguerra R, Alberti H, Salem LB, et al. The global diabetes pandemic: the Tunisian experience. Eur J Clin Nutr 2007;61:160-5.

35. Tazi MA, Abir-Khalil S, Chaouki N, et al. Prevalence of the main cardiovascular risk factors in Morocco: results of a National Survey, 2000. J Hypertens 2003;21:897-903.

36. Biad A, Makhlouf L, Atif A, et al. The prevalence of diabetes and hypertension in East of Algiers. J Hypertension 2010;28:318-9.

37. Richard J-L. Le pied diabétique: fréquence, coût dépistage et prévention. J Plaies Cicatrisations 1997;7:127-31.

38. Benotmane A, Mohammedi F, Ayad F, et al. Diabetic foot lesions: etiologic and prognostic factors. Diabetes Metab 2000;26:113-7.

39. Ducorps M, Baleynaud S, Mayaudon H, et al. A prevalence survey of diabetes in Mauritania. Diabetes Care 1996;19:761-3.

40. Erokhsi A, Ahmed S, Aribi N, et al. Diabetic foot lesions in Lybian population. Jamahiria medical journal 2004:9:262-7.

41. Elbagir MN, Eltom MA, Elmahadi EM, et al. A high prevalence of diabetes mellitus and impaired glucose tolerance in the Danagla community in northern Sudan. Diabet Med 1998;15:164-9.

42. Elbagir MN, Eltom MA, Elmahadi EM, et al. A population-based study of the prevalence of diabetes and impaired glucose tolerance in adults in northern Sudan. Diabetes Care 1996;19:1126-8.

43. Elbagir MN, Eltom MA, Mahadi EO, Elmahadi EM, et al. Pattern of long-term complications in Sudanese insulin-treated diabetic patients. Diabetes Res Clin Pract 1995;30:59-67.

44. Wiliam HH, Ronald EA, Mohmmad AA, et al. Diabetes mellitus in Egypt: risk factors, prevalence and future burden. East Mediterr Health J 1997;3:144-8.

45. Herman WH, Aubert RE, Engelgau MM, et al. Diabetes mellitus in Egypt: glycaemic control and microvascular and neuropathic complications. Diabet Med 1998;15:1045-51.

46. International Diabetes Federation (IDF). Diabetes Atlas. 3rd edn, 2006.

47. Wild S, Roglic G, Green A, et al. Global prevalence of diabetes: estimates for the year 2000 and projections for 2030. Diabetes Care 2004;27:1047-53.

48. Al-Habori M, Al-Mamari M, Al-Meeri A. Type II Diabetes Mellitus and impaired glucose tolerance in Yemen: prevalence, associated metabolic changes and risk factors. Diabetes Res Clin Pract 2004;65:275-81.

49. Al-Lawati JA, Al Riyami AM, Mohammed AJ, et al. Increasing prevalence of diabetes mellitus in Oman. Diabet Med 2002;19:954-7. 
50. Saadi H, Carruthers SG, Nagelkerke N, et al. Prevalence of diabetes mellitus and its complications in a population-based sample in Al Ain, United Arab Emirates. Diabetes Res Clin Pract 2007:78:369-77.

51. Alzurba FI, Al Garf A. Prevalence of diabetes mellitus among among Bahrainis attending primary health care centers. East Mediterr Health $J$ 1996;2:274-82.

52. Al-Mahroos F, Al-Roomi K. Diabetic neuropathy, foot ulceration, peripheral vascular disease and potential risk factors among patients with diabetes in Bahrain: a nationwide primary care diabetes clinicbased study. Ann Saudi Med 2007;27:25-31.

53. Alnesf $\mathrm{Y}, \mathrm{Kamel} \mathrm{MI}$ ES. A survey of risk factors for chronic non communicable disease: Ministry of health Kuwait, 2008.

54. Mansour AA, Wanoose HL, Hani I, et al. Diabetes screening in Basrah, Iraq: a population-based cross-sectional study. Diabetes Res Clin Pract 2008;79:147-50.

55. Abbas AM. Chronic complications of diabetes in Iraq: experience from southern Iraq. Clin Med Insights Endocrinol Diabetes 2009:1-9.

56. Albache N, Al Ali R, Rastam S, et al. Epidemiology of Type 2 diabetes mellitus in Aleppo, Syria. J Diabetes 2010;2:85-91.

57. Hirbli KI, Jambeine MA, Slim HB, et al. Prevalence of diabetes in greater Beirut. Diabetes Care 2005;28:1262.

58. Taleb N, Salti H, Al-Mokaddam M, et al. Vascular complications of diabetes in Lebanon: experience at the American University of Beirut. Br J Diabetes Vasc Dis 2008;8:80-3.
59. Ajlouni K, Khader YS, Batieha A, et al. An increase in prevalence of diabetes mellitus in Jordan over 10 years. J Diabetes Complications 2008;22:317-24.

60. Jbour AS, Jarrah NS, Radaideh AM, et al. Prevalence and predictors of diabetic foot syndrome in type 2 diabetes mellitus in Jordan. Saudi Med J 2003;24:761-4.

61. Alnozha MM, Almaatouq MA, Almazrou YY, et al. Diabetes in Saudi Arabia. Saudi Med J 2004;25:1603-10.

62. Famuyiwa OO, Sulimani RA, Laajam MA, et al. Diabetes mellitus in Saudi Arabia: the clinical pattern and complications in 1,000 patients. Ann Saudi Med 1992;12:140-51.

63. Alwakeel JS, Sulimani R, Al-Asaad H, et al. Diabetes complications in 1952 type 2 diabetes mellitus patients managed in a single institution in Saudi Arabia. Ann Saudi Med 2008;28:260-6.

64. Husseini A, Abdul-Rahim $\mathrm{H}$, Awartani $\mathrm{F}$, et al. Prevalence of diabetes mellitus and impaired glucose tolerance in a rural Palestinian population. East Mediterr Health J 2000;6(5-6):1039-45.

65. Harrington $\mathrm{C}$, Zagari MJ, Corea J, et al. A cost analysis of diabetic lower-extremity ulcers. Diabetes Care 2000;23:1333-8.

66. Stockl K, Vanderplas A, Tafesse E, et al. Costs of lowerextremity ulcers among patients with diabetes. Diabetes Care 2004;27:2129-34.

67. Barceló A, Aedo C, Rajpathak S, et al. The cost of diabetes in Latin America and the Caribbean. Bull World Health Organ 2003;81:19-27.

68. Oksuz E, Malhan S, Sonmez B, et al. Cost of illness among patients with diabetic foot ulcer in Turkey. World J Diabetes 2016;7:462-9. 